\title{
THE BONE CHANGES OCCURRING IN RENAL AND COELIAC INFANTILISM AND THEIR RELATIONSHIP TO RICKETS
}

\author{
Part II. COELIAC RICKETS.* \\ BY
}

LEONARD G. PARSONS, M.D., F.R.C.P.

Physician to the Children's Hospital, Birmingham.

The occurrence of bone deformities in coeliac disease appears completely to have escaped recognition until within recent years ; a somewhat remarkable fact considering the frequency and the occasional great severity of these changes. Probably some of the cases have not been recognised as due to coeliac disease, and have thereby helped to swell that inchoate group of bone disorders called "late rickets." Another possible explanation of the discrepancy may be found in the fact that many of the earlier descriptions of coeliac disease were instances of the disease occurring in young children, whereas bone deformities do not usually develop before the age of seven years. The stunting of growth and resulting infantilism have, however, been commented upon by many writers, and indeed Gee, in his original description of the disease drew attention to this symptom.

Coeliac infantilism may be defined as the arrest of development and stunting of growth which occurs in that form of severe chronic intestinal indigestion described by Gee and which is characterised by a high grade of defective fat absorption and carbohydrate intolerance.

In the year 1913 when showing a case of coeliac disease before the Midland Medical Society $\left({ }^{1}\right)$ I expressed the opinion that rickets was not an uncommon complication of coliac disease. As far as I can discover this is the first reference to the occurrence of bone deformities in that disease, although in the previous year McCrudden and Fales $\left({ }^{2}\right)$ had described a case of coeliac disease in a boy aged ten years whose bones showed osteoporosis, fragility and fractures. A contrary view was, however, expressed by $\operatorname{Still}\left({ }^{3}\right)$ who, in his Lumleian Lectures, said : " It is indeed a remarkable fact that rickets is rarely found in spite of the long enduring disturbance of nutrition produced by coeliac disease" ; although he did refer to the complication of "late rickets" developing in one çase at the age of eight, a girl whose legs at this age began to bend rapidly " so that much distortion occurred, crippling the child." Miller $\left({ }^{4}\right)$ in 1920 , in describing a case which showed definite rachitic changes, wrote: "So far as I know such a condition has not previously been described in connection with coeliac infantilism. It is curious that in this disease in which the absorption of fat is so conspicuously defective changes in the long bones are so much less frequent than in renal infantilism. Perhaps the minor manifestations of rickets are missed." Marriott $\left({ }^{5}\right)$ agrees that rickets is not a frequent complication of coeliac disease" a slight degree of rickets is often observed but no more than in the case of any other malnourished infant or child. Severe rickets is rarely observed in patients with coeliac disease." On the other hand, J. H. Hess, whose original paper I have not been able to consult, is quoted by $\mathrm{Abt}\left({ }^{6}\right)$ as saying that rickets was demonstrable in most of his cases. Lichtenstein $\left({ }^{7}\right)$ also

* Part I, "Renal Rickets," was published in ARCH. Dis. ChILd., Vol. II, No. 7, p. 1. 
denies that there is any connection between rickets and coeliac disease, but nevertheless found that out of a total of nine cases two showed slight, and three severe rickets. In $1925 \operatorname{Lehman}\left({ }^{8}\right)$ wrote a paper on the bone changes in coeliac disease which was based on a study of three patients all of whom showed osteoporosis and also developed rickets at a very late period of the disease. The most recent contribution to this subject is by Lehndorff and Mauntner $\left({ }^{9}\right)$ who in the course of a comprehensive paper on coeliac disease express the opinion that rachitic bone changes do not occur at all frequently, although they admit that severe forms of rickets may occur at the height of the disease.

In my opinion bone changes are of frequent occurrence in severe cases of coeliac disease, provided that the disease be one of long standing. In not a few cases deformity of moderate degree occurs ; rarely there are very severe deformities with multiple fractures. I hope to show in the course of this paper that these changes are rachitic in origin, that they are curable, and that their onset can be prevented.

\section{Clinical Characteristics.}

The children, of course, present the characteristic appearances associated with coeliac disease, i.e., pallor, loss of weight, enlarged and atonic abdomen, limbs that are flabby, wasted, slender and hypotonic ; and marked arrest of development. The most common bone deformity is genu valgum which varies in degree but which may eventually become so severe that the child " goes off its legs " entirely. Associated with the genu valgum, but sometimes occurring independently of it, there may be some enlargement of the epiphyses of the wrists. Whilst these are the commonest manifestations, the deformities may reach a degree which eclipses the severest grade of rickets which I have seen.

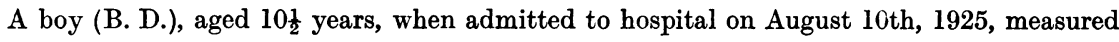
$38 \frac{1}{2}$ inches in length and was unable to walk or to lift himself into a sitting from a prone position, although if sat up he could retain his position. The ribs showed a very marked rosary, the costo-chrondral junctions being enormously enlarged. There was a deep Harrison's sulcus and extreme eversion of the ribs. The whole thorax was small, appeared shrunken, and contrasted greatly with the large and distended abdomen. The clavicles were bent almost to a right angle at the junction of their inner and middle thirds. A degree of kyphosis was present. The humeri showed extreme bending to a point just below the surgical neck, and there was marked enlargement of the epiphyses at the lower. end of the radius and ulna on both sides. On the left side there had obviously been a fracture of the lower ends of the radius and ulna with displacement of the bones. The tibiæ and fibulæ appeared fairly straight, but the epiphyses showed some enlargement, and the femora showed severe antero-posterior curvatures.

Bone deformities do not occur unless the disease is severe in type and of long standing, and unless the child has passed the age of seven years. Associated with these bone changes there may be attacks of tetany, a combination more frequently observed in coeliac than in renal rickets. Lehndorff and Mauntner $\left({ }^{9}\right)$ drew attention to the fact that in two of their cases the children showed markedly blue sclerotics. One of my cases also showed this peculiarity but the sclerotics gradually became more normal in colour, and now, some two and a half years after the colour was first noted, they appear normal. The blueness was, however, never of the characteristic homogeneous leaden blue colour that is seen in association with fragilitas ossium. 


\section{Radiographic ApPearances.}

The radiographic appearances of the bones in coeliac disease vary considerably but from a study of them it is, I think, possible to arrive at the method by which the rachitic deformities develop, and also it is possible to watch the process of cure. Still $\left({ }^{3}\right)$ states that skiagrams of the limbs in three cases showed that the " bones were unduly small, corresponding to the small stature of the child, but none showed any abnormality in the formed bone, the trabecular structure was well marked and the outer layer appeared to be normal in thickness and density. They all showed, however, a marked departure from the normal for the age, in respect of the centres of ossification in the epiphyses ... There is ... a notable absence of the usual appearance of rickets." The ages of these children are not given, and for reasons which I shall give later this is an important point. If the child be under seven years of age there probably will not be any evidence of rickets, but the bones look unduly small even allowing for the small stature of the child. The trabeculæ may be well formed but should the disease have been present for any length of time the trabeculæ appear to be thinner and the whole bone more osteoporotic and fragile than normal. The cortex also is thinner than would be expected but the epiphyseal line is quite sharp and distinct.

In the case of a child (M. C.), aged 4 years, who had suffered from coeliac disease for three years, my colleague, Dr. Teall, reported as follows : "The radiogram shows very little calcium in the bones which have an atrophic appearance, there is no rickets" (Fig. 1); and again on January 3rd, 1927, that there was marked bone atrophy and that the bones appeared decalcified.

Lehndorff and Mauntner say that this osteoporosis is a very typical occurrence in the course of coeliac disease and that if radiograms were systematically taken in all cases such bony changes would almost constantly be observed, an opinion with which I am in complete agreement.

The earliest evidence of rickets occurs in a bone not very dissimilar from the foregoing, the lower ends of the radius and ulna are slightly enlarged, the spongy tissue a little more open, and there is a slight irregularity at the epiphyseal line. In this form fractures may be present as in the radiogram reproduced (Fig. 2). This was taken from a girl aged ten years, the duration of whose symptoms of coeliac disease was unknown but who had suffered from repeated attacks of tetany since the age of seven.

In a case of moderate severity the radiographic appearances are very striking (Fig. 3). In addition to the delay in the centres of ossification noted by Still the whole bone is atrophic, fragile and osteoporotic. The cortex is thin and the trabecular mesh-work more open and delicate than usual. At the end of the diaphysis there is a well marked metaphysis. The metaphysis . is perhaps not quite so splayed out as in ordinary rickets but otherwise there is no difference between the two conditions. Not infrequently in the neighbourhood of the metaphysis are transverse striations : the causation of these has been the subject of some recent investigations to which reference will be made later. Single or multiple, complete or incomplete, fractures of the shaft of the bone are frequently observed. A study of the radiograms (Figs. 3 and 13) 
will show the type of changes found better than any written description, and also demonstrates the essential similarity between this condition and what $I$ have called the "atrophic type" of renal rickets.

The radiograms of B. D. show the severest type of coeliac rickets (Figs. 4 and 15-22). When this child was admitted to hospital his bones were so lacking in calcium that it was difficult to obtain a satisfactory radiogram. The osteoporosis was of extreme degree, the cortex of the bone excessively thin and the spongy tissue thin and spidery; indeed, in many areas it was practically non-existent. There were numerous fractures of the ulna and radius, and it was seen that the marked bending of the humeri and the left radius to which reference has already been made were due to fractures. In this instance the usual appearance of a rachitic metaphysis, i.e., the swollen extremity of the diaphysis with an irregular fluffy margin, was not seen. The metaphysis did not appear to be swollen and the end of the diaphysis appeared relatively straight, but at a very much greater distance than usual from the epiphysis. The end of the diaphysis did not, however, present that clear cut sharp outline which occurs in coeliac infants under seven years of age in whom there is not any evidence of rickets; but the picture was essentially what has been described by Wimberger $\left({ }^{10}\right)$ as the "passive type" of rickets. During the process of cure in this case the radiograms approached more closely the appearance characteristic of examples of moderate severity, and the metaphysis lost the appearance of the "passive type" and became more like the usual type of rachitic metaphysis.

The criticism may be made that these radiographic appearances are not those of true rickets, but I would reply that if the radiogram (Fig. 4) be compared with a radiogram (Fig. 5) which was taken from an undoubted case of severe uncomplicated rickets, the picture is seen to be essentially the same.

The series of radiograms (Figs. 1-4) show in my opinion the various stages in the development of the severest type of coeliac rickets. The process and completeness of the cure is also shown in the radiograms reproduced (Figs. 6-12 and 15-22). During the process of the cure the development of transverse striations in the neighbourhood of the metaphysis may be observed (see Figs. 13 and 14). Even after cure is complete the bone is still fragile and osteoporotic, the trabecular network more delicate and the cortex thinner than in the normal bone; but there is no sign of rickets. In this connection it is interesting to note the statement of Park $\left({ }^{11}\right)$ to the effect that although cod liver oil will cure low-calcium rickets, yet it never restores the finer structure of the bone to normal.

The Effect of Growth on the Production of Rickets. Assuming that the deformities are rachitic in nature and that they are due to defective fat absorption, it may well be asked why these changes do not occur in all cases of coeliac disease. I have already stated that these changes are only of frequent occurrence in severe and prolonged cases : these children have in many instances not received efficient treatment. Although such treatment means that the child must be given a so-called fat-free dietary, which is in reality a diet low in fat, yet it does assure the absorption of a certain amount of fat. Thus in one instance when the patient was taking skimmed protein milk only, the fat intake per 24 hours was $7 \cdot 74 \mathrm{~g}$., of which $94 \cdot 7$ per cent. was absorbed (see O.A., Table 1) ; whereas if efficient dietetic treatment has not been instituted less fat is absorbed because the disease is more likely to be severe and diarrhœa to occur. It is also possible that in the absence of limitation of carbohydrates a fermentative diarrhœa with consequent non- 
absorption of fat will develop. Dietetic treatment does not, however, always prevent the development of rickets, a fact to which attention is drawn under the heading of treatment.

One of the most striking characteristics of coeliac rickets is its nondevelopment before the age of seven years, and its occurrence even at that age only after the disease has been present in a severe form for a considerable time. The explanation of this phenomenon is almost certainly that as long as the child does not grow to any extent rickets will not occur, but that when a period of more active growth arrives, even if that activity be greatly depressed by reason of coeliac disease, rickets will develop. In Part I of this paper the work of Holt, La Mer, and Chown on calcification was quoted, and it was stated that these workers defined rickets " not as a state in which the concentrations of calcium and phosphate are so low that $\mathrm{Ca}_{3}\left(\mathrm{PO}_{4}\right)_{2}$ cannot be precipitated, but as a state in which as the result of lowered ion concentration $\mathrm{Ca}_{3}\left(\mathrm{PO}_{4}\right)_{2}$ is deposited so slowly that the new bone production exceeds in its rapidity, and consequently uncalcified bone or osteoid tissue is produced." In this view, therefore, if growth does not occur, rickets is not likely to develop, even though the ionic concentration be far below that at which rickets usually occurs.

The effect of growth in the production of rickets is probably a factor of very considerable importance. It is well known that children who suffer from infantile atrophy do not develop rickets during that period. McCollum and his associates found that starvation produced healing of rickets in rats, and thought that this effect was due to the liberation into the blood stream of phosphorus derived from disintegrated protoplasm, e.g., muscle, which caused calcium deposition to occur. They came to the conclusions that the starving body is capable of readjusting abnormal relations within itself, and that therein lay the reason why the athreptic child does not develop rickets. I do not think that this can be the correct explanation of the rarity of rickets in atrophic infants when compared.with its incidence in other infants of the same age and fed on similar dietaries. I believe that the real solution of the problem of the non-development of rickets in atrophic children is to be found in their lack of growth : " the athreptic child is too busy trying to hold on to life to grow, and not growing-develops no rickets." (13) The parallelism between infantile atrophy and coeliac disease is not, however, quite a complete one, because in the former, with very rare exceptions, the absorption of calcium, phosphorus and fat is normal. Now although defective fat absorption is the cause of coeliac rickets, yet its occurrence also spells starvation and therefore leads to arrest of growth. These two factors (defective fat absorption and starvation) may neutralise one another and prevent the development of rickets until growth occurs ; or to put the same proposition in other words, absorption of calcium and phosphorus, although greatly diminished, appears to be sufficient to calcify the fragile bones of coeliac disease so long as there is little or no growth, but directly any considerable growth occurs this defective absorption results in the development of rickets. Once rickets has manifested itself healing does not appear to occur until the coeliac disease be cured, or unless adequate treatment be carried out, even if growth should again come to a standstill. 
Transverse Striations in the Neighbourhood of the Metaphysis.-The frequent occurrence of these striations in coeliac rickets has already been commented upon. The significance of them has been studied by Harris $\left({ }^{13}\right)$ who holds the view that they constitute evidence of arrest of growth. His observations both on their own merit and because they have received the imprimatur of Elliot Smith(14) require careful consideration. According to Harris these lines occur normally in adolescence and in all cases of marked decrease in the rate of growth from any form of acute illness or starvation; they may also occur with seasonal variations in the rate of growth, or as a part of the healing process of rickets. In his view the well-known "line test" of healing rickets is a manifestation of arrest of growth and not, if I understand him aright, a manifestation of healing of rickets. This surely is incorrect, for it is found experimentally that when foods containing Vitamin D are added to the dietary of a rachitic animal, coincidentally with the appearance of the white line growth begins to occur, so that the white line must indicate activity and not arrest of growth. Harris may have more conclusive evidence to prove his theory than he gives in his paper, for the illustrative case quoted is far from convincing. The case was that of a child aged two years and eight months who in three successive years had three distinct illnesses, and who on X-ray examination showed two transverse lines at the lower end of the diaphysis of the femur and the upper and lower ends of the diaphysis of the tibia. The lines were also seen at the shoulder and wrist. These two lines are regarded, but without any proof whatsoever, as being formed during the first and second periods of acute illness. The child later developed a severe attack of bronchopneumonia, and seven weeks after its onset a radiogram showed a third series of lines of dense bone formed near the metaphysis almost at the ends of the diaphyses. This observation appears to be the only one which can really be cited as evidence in favour of his view, and it does not appear to be sufficient upon which to base his theory. He also makes the statement that the occurrence of these transverse lines has never been reported in cases of genu valgum and it is, therefore, of interest to note their development during the course of recovery in one of my cases (M.R.), a girl who developed such an extreme degree of genu valgum that walking became impossible. These striations are most marked in the radiogram (Fig. 14) taken at the time when the cure of her rickets was completed, and which was, incidentally, the end of the most active period of growth since the onset of coeliac disease. In this instance transverse striations did not develop in the ulna nor in the radius.

The occurrence of transverse striations in coeliac disease is also referred to by Lehmann ( $\left.{ }^{8}\right)$ who in the course of his description of his case "says- " in the distal epiphyses of the radius and ulna there are also to be seen a striatification consisting of multiple horizontal lines, so-called 'year rings.' These year rings seem suspicious of past rickets. They are no proof of it, however, since they occur in other nutritional disturbances of the bone." According to A. F. Hess $\left({ }^{15}\right)$ the explanation of the development of these transverse lines "which have been noted and described so frequently in the epiphyses of infants" has always been lacking, but as a rule they have been attributed to 
remission in the course of the rachitic process. Now Hess has shown that by giving small amounts of phosphorus to rats, a transverse layer of dense compact osseous tissue immediately adjacent to the proliferating cartilage is produced. The phosphorus, however, is unable to prevent the occurrence of rickets or to exercise any curative effects if rickets be already present. In other words, while phosphorus is able to stimulate calcification at the epiphyses, it is unable to calcify the preparatory cartilage or osteoid tissue. As a result of these observations this writer questions whether some of the transverse striations may not be occasioned by irritative substances similar in action to elementary phosphorus. He has observed these lines develop in infants whose diet and general hygienic surroundings were unchanged, and this has occurred not only during spring and summer but also in the winter months.

I cannot myself offer any evidence as to the cause of the striations, although I have observed them in coeliac disease and other conditions for many years, and I have also pointed out their occurrence in renal infantilism. I have regarded them as representing a period in which better bone was laid down as a result of improvement in the general condition, rather than as an indication of arrest of growth. The case (M. R.), quoted above, lends some support to that view.

\section{Chemical Findings.}

The blood chemistry has been investigated in five severe cases of coeliac infantilism which have been under my observation in the course of the last two or three years. In four cases the blood calcium was low before light treatment was started, but rose under treatment, and in these cases there was also at some period a low blood phosphorus. In the remaining case (M. C.), a child who did not show active rickets, the blood calcium just reached the lower limit of the normal (9.0 mg. per cent.), and the phosphorus was $5.65 \mathrm{mg}$. per cent. The blood findings are, therefore, quite consistent with the view that the bone deformities are rachitic in origin. The occurrence of tetany as a complication of coeliac disease is also exactly what would be expected in view of the low values obtained for blood calcium.

Recently we have attempted to obtain an indication of the Ca-ion concentration of the blood serum by the method of ultra-filtration through collodion sacs under moderate pressure as described by Pincus, Peterson and Kramer( $\left.{ }^{16}\right)$. The sacs used were prepared from an eight per cent. solution of Schering's celloidin in equal parts of alcohol and ether. A fresh sac was used for each estimation, 2 cc. of serum being placed in the cell and a negative pressure of 120-125 mm. Hg. maintained for four hours. At the end of this time the calcium was estimated both in the ultra-filtrate and in the residual serum. The sum of the estimations of calcium inside and outside the cell was found to be the same as the total calcium with usually a less error than one to two per cent. Pincus and his co-workers assume that the calcium in the filtrate is ionised and they refer to this as. "free calcium"; and they regard the calcium which does not filter as bound to protein and practically un-ionised, and this portion they refer to as "bound oalcium," They found that the 
"free calcium" normally amounts to 50 or 60 per cent. of the total calcium, but that in tetany the "free calcium" may be diminished to 40 or 30 per cent. of this amount or even less.

The number of observations made by this method has not been very large but has included estimations in cases of tetany, coeliac and renal rickets, nephrosis, pink disease, and thrombocytopenic purpura. The blood-calcium figures vary so much in such a series of cases that it would appear better to express the "free calcium" in mg. per cent. rather than as a percentage of the total calcium. The results obtained on the whole have shown somewhat smaller values for "free calcium" than those obtained by Pincus, but they confirm his statement that in tetany the amount of "free calcium " is greatly diminished. In tetany it is apparently always less than 2.5 and usually less than $2.2 \mathrm{mg}$. per cent. Two cases of coeliac rickets, both of whom had suffered from frequent attacks of tetany, showed a low "free calcium" (2.2 and $2 \cdot 5 \mathrm{mg}$. per cent.) although at the time of these observations both were free from active rickets; whereas in the two other cases of coeliac disease, neither of which had been complicated by rickets or tetany, it was 3.2 and $3.9 \mathrm{mg}$. per cent. respectively (see Table I). Lathrop( ${ }^{17}$ ), writing on renal rickets, refers to a figure of $3.8 \mathrm{mg}$. per cent. as being normal, and in my normal cases the free calcium in nephrosis was $3 \cdot 2$, in pink disease $3 \cdot 8$, and in thrombocytopenic purpura $3.9 \mathrm{mg}$. per cent.

These observations therefore, although admittedly they are but few in number, support the suggestion that Ca-ion concentration is low in coeliac rickets, and that the bone changes are truly rachitic.

A complete record of the blood chemistry findings and also of the results of examination of the stools is shown in Table $\mathrm{I}$.

\section{Treatment.}

The fact that rickets may arise and develop progressively in a child while under treatment for coeliac disease was forcibly brought home to me in the case of a girl (M. R.) who developed coeliac disease in September, 1919, when she was five years old. She was placed on a fat-free dietary and given bile salts by the mouth, with the result that considerable improvement occurred; but in January, 1921, she developed the first of several attacks of tetany, and in May, 1922, genu valgum was noticed. From this time onwards, in spite of splinting, the deformity increased, and eventually in 1923, although her general condition had improved, walking became impossible. Radiograms (Fig. 6) taken in March, 1925, showed the changes already described as occurring in a case of moderate severity. Since the bone changes were apparently rachitic and progressive in character, it was decided to try the effect on them of ultra-violet irradiation. After two months of treatment it was obvious that healing had commenced and Dr. Teall reported as follows : "The bone condition appears to be improving, new bone is being laid down at the end of the metaphysis much as in healing rickets" (Fig. 7). The treatment was continued and healing slowly progressed until by the end of the year the rickets had completely healed and the child had begun to walk again. During 


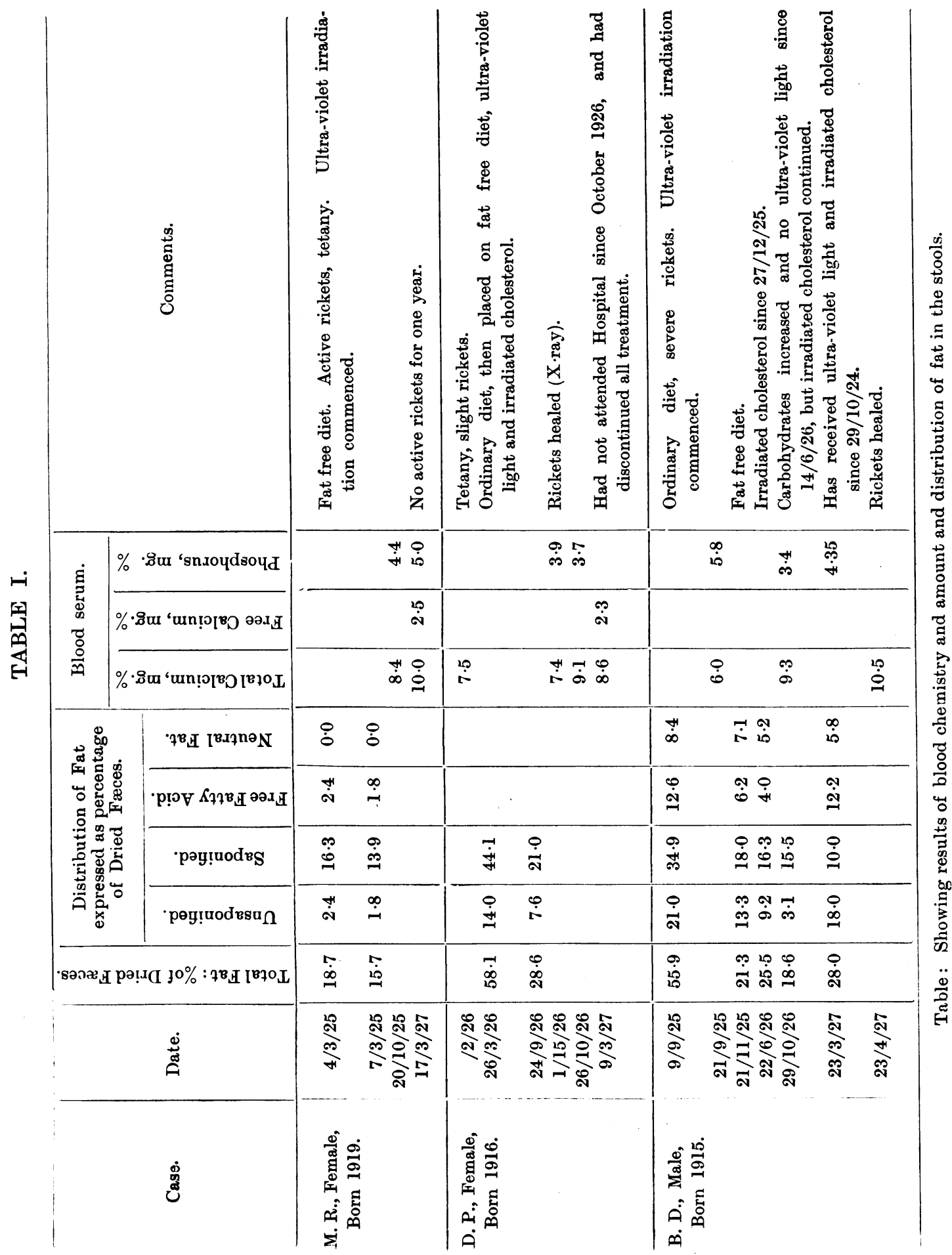




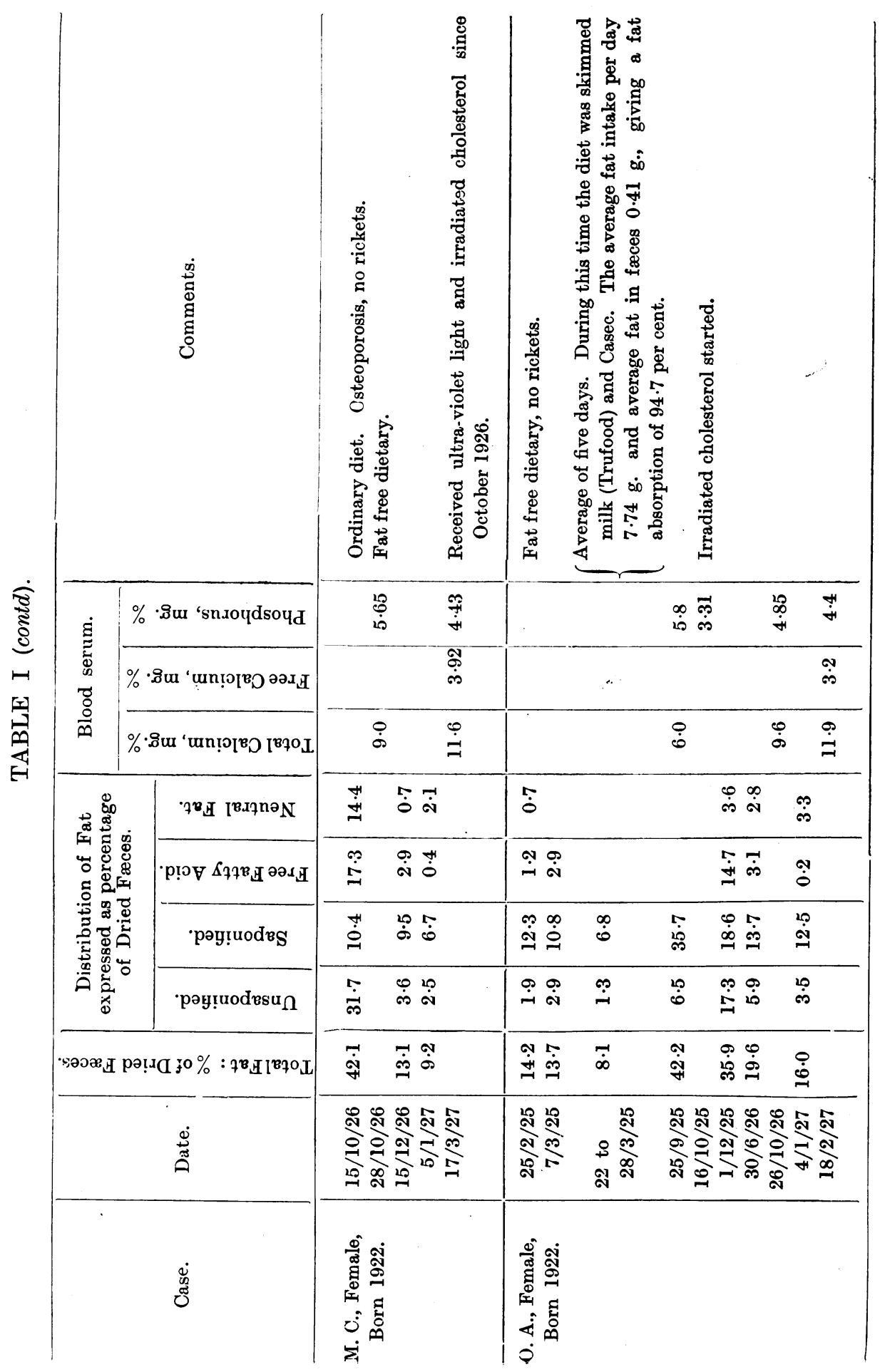


the year 1926 the treatment was continued and at the present time the child, although somewhat stunted in growth, looks well and has grown considerably. She is on normal diet, attends school, and can run and hold her own in play with other children. The knock knee is decidedly less marked than when treatment was first instituted in March, 1925 (see Figs. 8-14).

Even more striking have been the results of treatment in the case of B. D., whose clinical condition and radiograms on admission to hospital have already been described in detail (Fig. 4). This boy developed diarrhoea alba at three years of age, and when six years old was put into splints for knock knee. At eight years of age he had an attack of influenza followed by tetany and since that time had been unable to walk. He had apparently not been treated for coeliac disease before his admission to hospital at the age of ten and a half years, in August, 1925. He was given ultra-violet light treatment for two months from August to October, 1925, without the diet being modified in any way. A very slight but definite increase in calcification occurred during that time (Figs. 15-16). On October 12th he was given a "fat free" diet and the amount of carbohydrate food limited. During the next two months improvement continued and increased so that at the end of December some of the fractures had healed (Fig. 17) ; the rate of improvement was, however, slow, and in view of the good results obtained by giving irradiated cholesterol in ordinary rickets it was thought advisable to try it in this case. As liquid paraffin is unabsorbed by the intestine an attempt was made to use this as a vehicle, and the administration of a $2 \%$ solution of irradiated cholesterol in paraffin was therefore started on December 3rd, 1925, three drams of this solution being given three times a day. The child stood this well for a time but eventually the paraffin appeared to cause looseness of the bowels and from that time onwards the cholesterol was administered in powder form with the meals. After the addition of cholesterol the rate of recovery, although still slow, increased and was continuous (Figs. 18-19). On June 19th, 1926, he was discharged from hospital to his home. At this time his diet was relaxed somewhat as far as carbohydrates were concerned and ultra-violet light treatment was stopped, but the adminstration of irradiated cholesterol was continued and a radiogram taken on August 12th (Fig. 20) showed that he was steadily improving. He was seen again on October 28 th, 1926, when as will be seen from the radiogram (Fig. 21) the degree of healing of the bones was most marked. From this date until the present time he has been receiving ultra-violet light treatment as well as irradiated cholesterol and a radiogram (Fig. 22) taken on March 23rd, 1927, shows that the bones are practically healed. He first attempted to stand about April, 1926, and on his discharge from hospital in June he was able to walk a step or two with support. In October he was able to walk unaided and now he walks well, rides a tricycle one mile to school and has grown $1 \frac{1}{2}$ inches since treatment was first instituted. One or two other points of interest in this case may also be mentioned. During the time he was in hospital he had repeated attacks of bronchitis, but since October this liability appears to have completeiy disappeared and at the same time his thorax, which at the time of his admission to hospital appeared small 
and shrunken, has expanded and the rickety rosary which was such a conspicuous feature is very much less noticeable. Again, for some three or four years before he came under my care his hair had become harsh and grew but slowly, so that it needed cutting only about once in every eighteen months. The first indication of recovery noticed by the parents was that his hair became smooth and began to grow so that it was necessary to have it cut. The hair is now normal in texture and growth.

The advantage that ultra-violet light possesses over heliotherapy in the treatment of these cases, at least in the industrial areas of the Midlands, was well demonstrated in the foregoing case. Previous to his admission to the Children's Hospital this boy had received a thorough course of heliotherapy in a country hospital near Birmingham and was so pigmented that when I first saw him I thought he was a coloured child, but radiograms taken at that time (Fig. 4) showed no sign of healing.

In every case investigated the concentration of the blood phosphorus and calcium has increased during the process of treatment.

Finally, I would stress one other point in treatment, namely, the length of time required to effect a cure of rickets. In the first case to which I have referred, nine months of light treatment was required, and in the other eighteen months ; periods which contrast markedly with the time required for the cure of ordinary rickets.

There does not, therefore, appear to be any doubt but that the bone deformities of coeliac infantilism, even when of the most extreme degree, can be cured by exposure to ultra-violet light or by the adminstration of irradiated cholesterol, also that this can occur even when the patient is on a "fat-free" dietary and while the coeliac disease is still active. Further, I believe that by adopting this method of treatment in coeliac disease the onset of rickets can be prevented and it, therefore, now forms part of the routine treatment in cases which come under my observation.* One such case, aged four and a quarter years, has been under treatment for coeliac disease for three years, and during the last fifteen months of this period she has been receiving ultra-violet light treatment and irradiated cholesterol. Radiograms of her bones taken recently show a bone that is in my opinion far less atrophic than is usual in cases of this age, one indeed that can be regarded as almost normal for a child of her size. The value of ultra-violet light in the treatment of coeliac disease has been recently pointed out by Michelmore( $\left.{ }^{18}\right)$, but no reference was made to its effect on bone. The fact that cure does occur under light treatment is additional evidence that the bone deformities are of rachitic origin, but the necessity for such long periods of treatment before a cure is obtained is proof that the condition is not simple uncomplicated rickets.

I would therefore submit that the evidence produced, namely, (1) the result of X-ray examination, (2) the blood calcium and phosphorus values, (3) the clinical characteristics, (4) the occurrence of tetany and (5) the results

* Irradiated ergosterol, made up with a chocolate basis, has now been substituted for irradiated cholesterol in the routine treatment of coeliac disease. 
of treatment by ultra-violet light and irradiated cholesterol, constitutes a convincing proof that the bony changes in coeliac infantilism are rachitic in origin.

In Part I of this paper I pointed out that the bone deformities of renal infantilism were those of true low-calcium rickets. In coeliac disease also, although the blood phosphorus is low, the deformities signify low-calcium rickets, and this is the explanation of the frequent occurrence of tetany in association with coeliac rickets. The development of rickets in coeliac infantilism is due primarily to the deficient absorption of fat and therefore of Vitamin D, calcium and phosphorus. This defect of absorption is probably also the cause of the poorly calcified atrophic and osteoporotic bone seen before rickets appears ; indeed in a case of this type McCrudden and Fales( ${ }^{2}$ ) actually found a negative calcium balance. Although in such a bone rickets is not manifest, yet the bone is potentially a rachitic one and only awaiting a period of growth actually to declare itself.

I have great pleasure in expressing once again my indebtedness to my colleagues Dr. C. G. Teall, Radiographer, and Dr. E. M. Hickmans, Biochemist to the Children's Hospital, Birmingham, for their help in the preparation of this paper, and to the Medical Research Council for defraying part of the expenses of the investigations.

\section{Conclusions.}

1. The bone deformities of coeliac infantilism are rachitic in nature. Although the blood phosphorus is low the rickets is of the low calcium type ; which is the explanation of the frequent occurrence of tetany.

2. The evidence that the bone deformities are rachitic is based on: $(a)$ the clinical characters, $(b)$ the results of blood examinations, $(c)$ the radiogram, and $(d)$ the result of treatment by ultra-violet light and irradiated cholesterol.

3. The cause of coeliac rickets is to be found in defective fat absorption, with resultant defective absorption of Vitamin $\mathrm{D}$, calcium and phosphorus.

4. The osteoporotic bone is a stage in the development of active rickets.

5. Growth is an important factor in the development of the bone deformities.

6. Coeliac rickets can be completely cured, even when the patient is on a fat-free dietary, by ultra-violet light irradiation and/or the administration of irradiated cholesterol.

\section{REFERENCES.}

1. Parsons, L. G., Birmingham Med. Rev., 1913, LXXIV, 33.

2. McCrudden, F. H., and Fales., H. L., J. Exp. Med., N.Y., 1912, XV, 450.

3. Still, G. F., Lancet, Lond., 1918, i, 163, 193 and 227.

4. Miller, R., Ibid., 1920, ii, 894.

5. Marriott, W. M., Abt's Pediatrics, Philad., III, 386.

6. Hess, J. H., quoted Pediatrics. (Practical Medicine Series), Chic., 1926, 37.

7. Lichtenstein, A., Acta Paed. Upps., 1921, I, 105.

8. Lehmann, F., Monatschrift. f. Kinderh. Orig., 1925, XXX, 124.

9. Lehndorff, H. and Mauntner, H., Ergeb. der Inn. Med. und Kind., Berl., 1927, XXXI, vi, 456. 
10. Wimberger, H., Studies of Rickets in Vienna 1919-22, Lond., 1923.

11. Park, E. A., Physiol. Rev., Balt., 1923, III, 106.

12. McCollum, E. V., Simmonds, N., Shipley, P. G. and Park, E. A., Bull. Johns Hopkins Hosp., Baltimore, 1922, XXXIII, 31.

13. Harris, H. A., Arch. Int. Med., Chic., 1926, XXXVIII, 785.

14. Smith, G. Elliot, Brit. Med. J., Lond., 1926, II, 815.

15. Hess, A. F., Amer. J. Dis. Child., Chic., 1926, XXXII, 483.

16. Pincus, J. B., Peterson, H. A. and Karmer, B., J. Biol. Chem., N.Y., 1926, LXVIII, 601.'

17. Lathrop, F. W., Arch. Int. Med., Chic., 1926, XXXVIII, 612.

18. Michelmore, L., Lancet, Lond., 1926, ii, 1264.

\section{LIST OF ILLUSTRA'TIONS.}

Figs. 1-4.-A series of radiograms showing the probable stages in the development of the severest form of coeliac rickets. All these radiograms show delay in the appearance of centres of ossification.

Fig. 1.-Radiogram (taken 23/10/26, of M. C., born 1922) showing the atrophic and osteoporotic character of the bones, the thin cortex, fragile trabeculæ but sharp epiphyseal line of the pre-rachitic stage.

Fig. 2.-Radiogram (taken February 1926, of D. P., born 1916) showing the earliest signs of rickets. The lower ends of the radius and ulna are slightly enlarged, the spongy tissue is more open and there is slight rachitic irregularity of the epiphyseal line. There is a fracture of the shaft of the ulna.

Fig. 3.-Radiogram (taken 10/3/25, of M R., born 1919) showing the moderately severe stage of coeliac rickets. The bones are atrophic and show osteoporosis. The cortex is thin, there is an open and delicate trabecular mesh work and a well marked rachitic metaphysis.

Fig. 4.-Radiogram (taken $12 / 8 / 25$, of B. D., born 1915) showing the severest type of coeliac rickets. The bones show extreme osteoporosis particularly manifest in the metacarpals and phalanges, and there are multiple fractures of the ulna and radius. The rachitic metaphysis is not obvious, the picture being that of the "passive type" of rickets.

Fig. 5.-Radiogram from a severe case of uncomplicated rickets in a child aged $2 \frac{1}{2}$ years. This radiogram shows a marked similarity to the radiogram of severe cœliac rickets shown in Fig. 4. Figs. 6-12.-A series of radiograms showing stages in the complete cure of a case (M. R.) of moderately severe coeliac rickets. The dates on which the various radiograms were taken are as follows : Fig. 6, 10/3/25; Fig. 7, 25/5/25 ; Fig. 8, 21/7/25; Fig. 9, 21/10/25 ; Fig. 10, $8 / 12 / 25$; Fig. 11, 14/4/26 and Fig. 12, 24/1/27.

Fig. 13.-Radiogram of lower end of femur and upper ends of tibia and fibula of M. R., taken 10.3 .25 , showing osteoporosis and rickets with some indication of transverse striations.

Fig. 14. - Radiogram of M. R., taken 14/4/26, for comparison with Fig. 13. The rickets is now healed and well marked transverse striations have formed.

Figs. 15-22.-A series of radiograms showing the stages in the complete cure of a case of severe coeliac rickets (B. D.). The dates in which these radiograms were taken are as follows : Fig. 15, $18 / 8 / 25$; Fig. 16, 13/10/25 ; Fig. 17, 23/12/25 ; Fig. 18, 24/3/26 ; Fig. 19, 8/6/26 ; Fig. 20, $12 / 8 / 26$; Fig. 21, 28/10/26 ; Fig. 22, 23/3/27.

Ultra-violet irradiation was commenced on $18 / 8 / 25$, continued until $19 / 6 / 26$, and restarted on $28 / 10 / 26$. The diet was "fat free" from $13 / 10 / 25$; from $23 / 12 / 25$ irradiated cholesterol was given. 


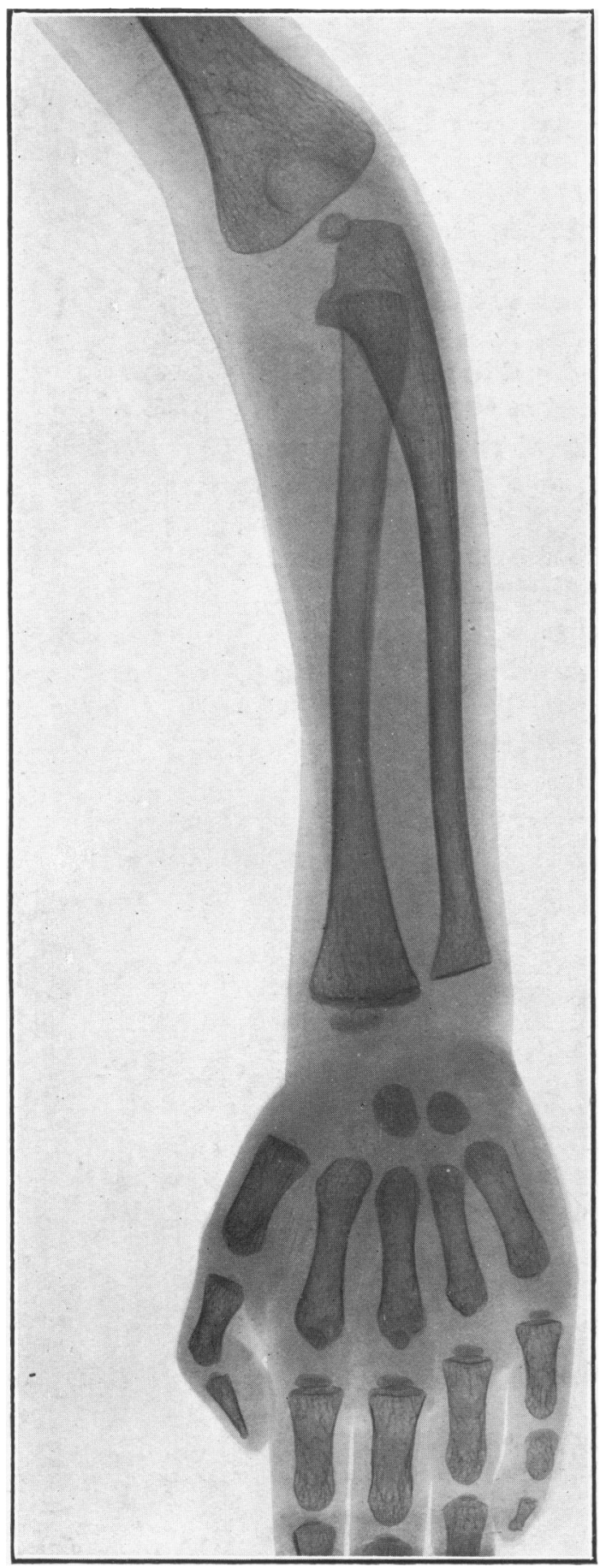

Fig. 1.

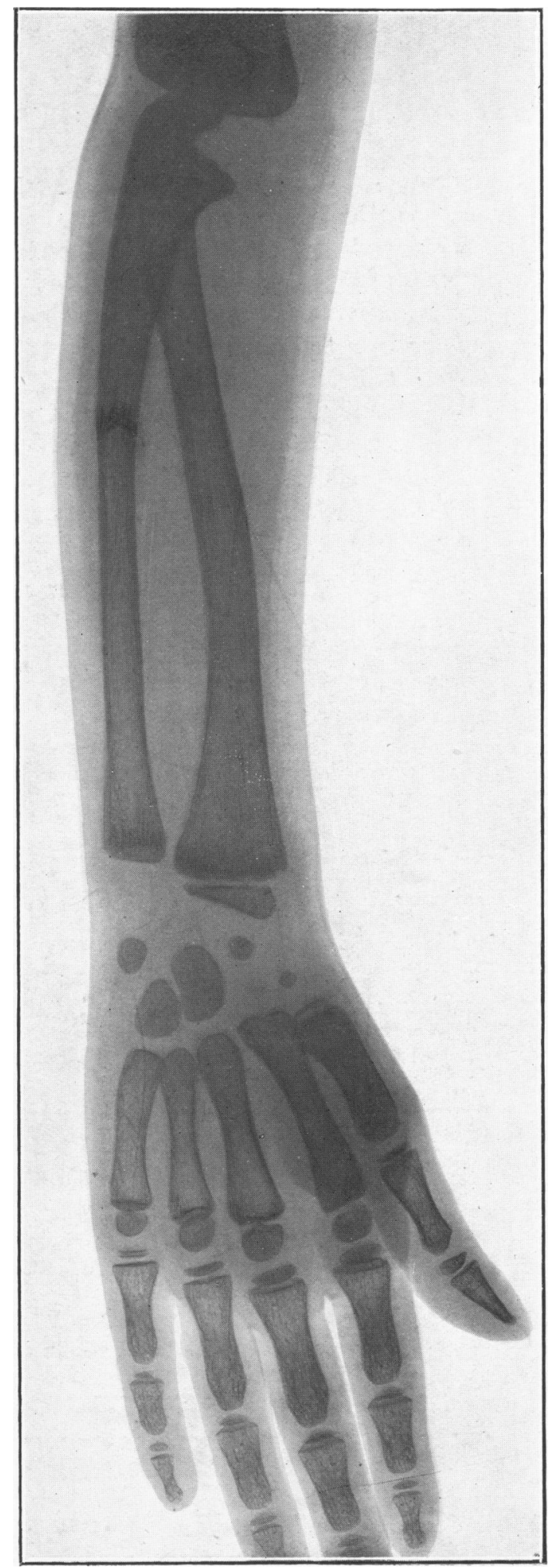

Fig. 2. 

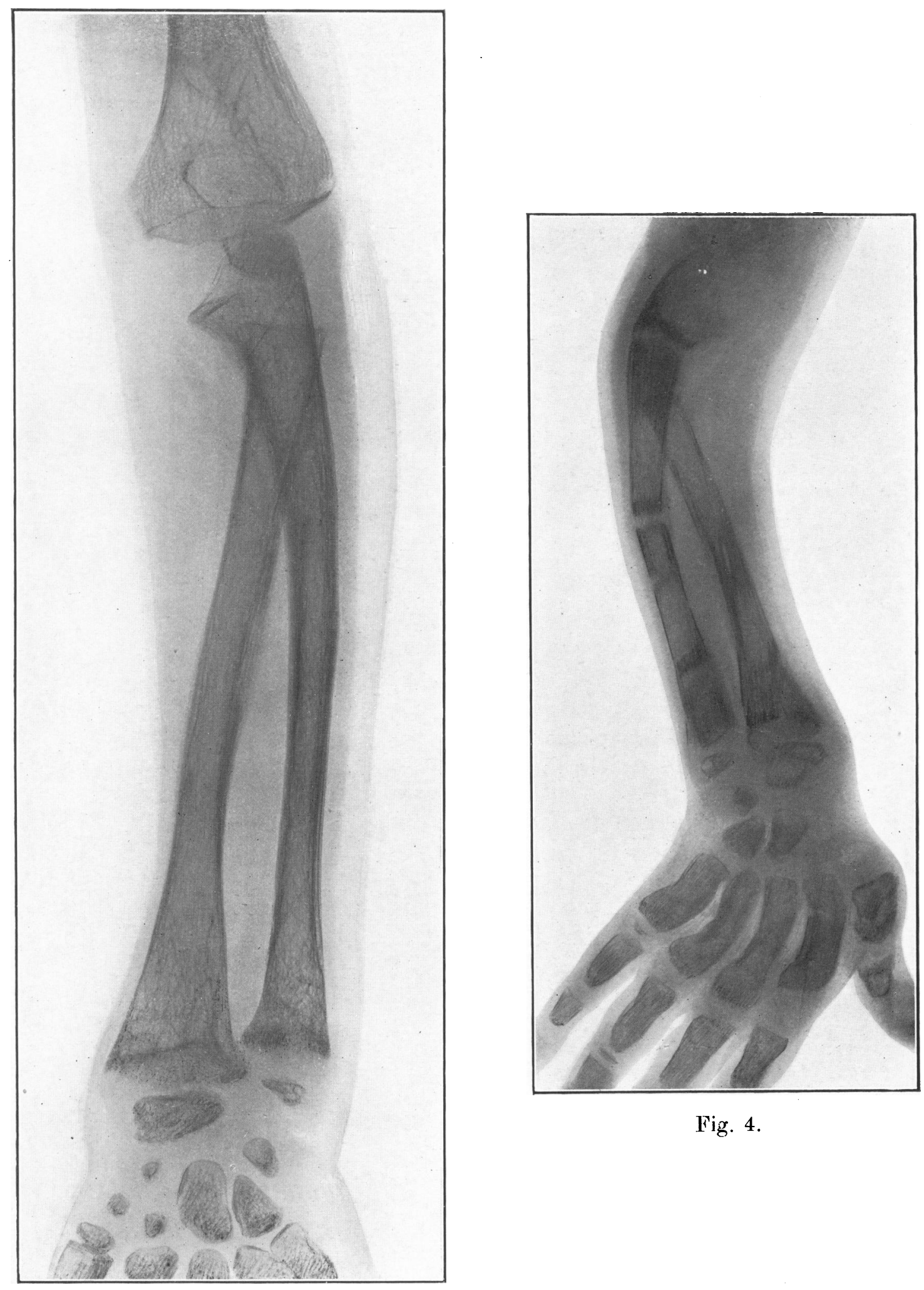

Fig. 4.

Fig. 3. 


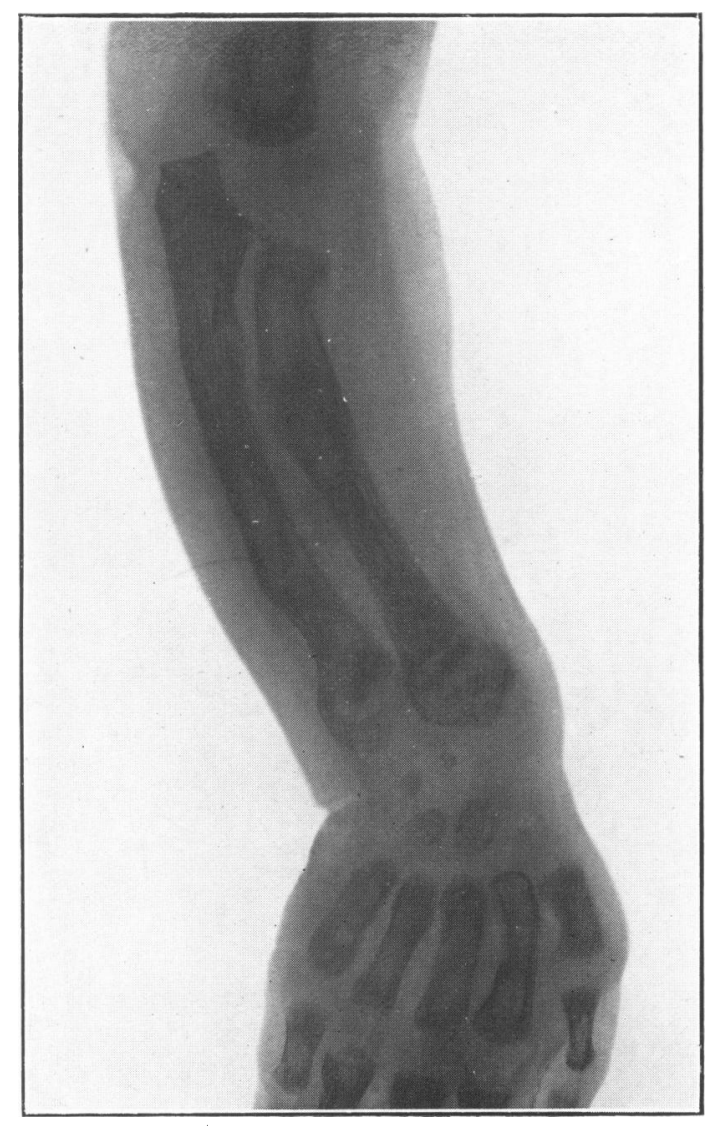

Fig. 5.

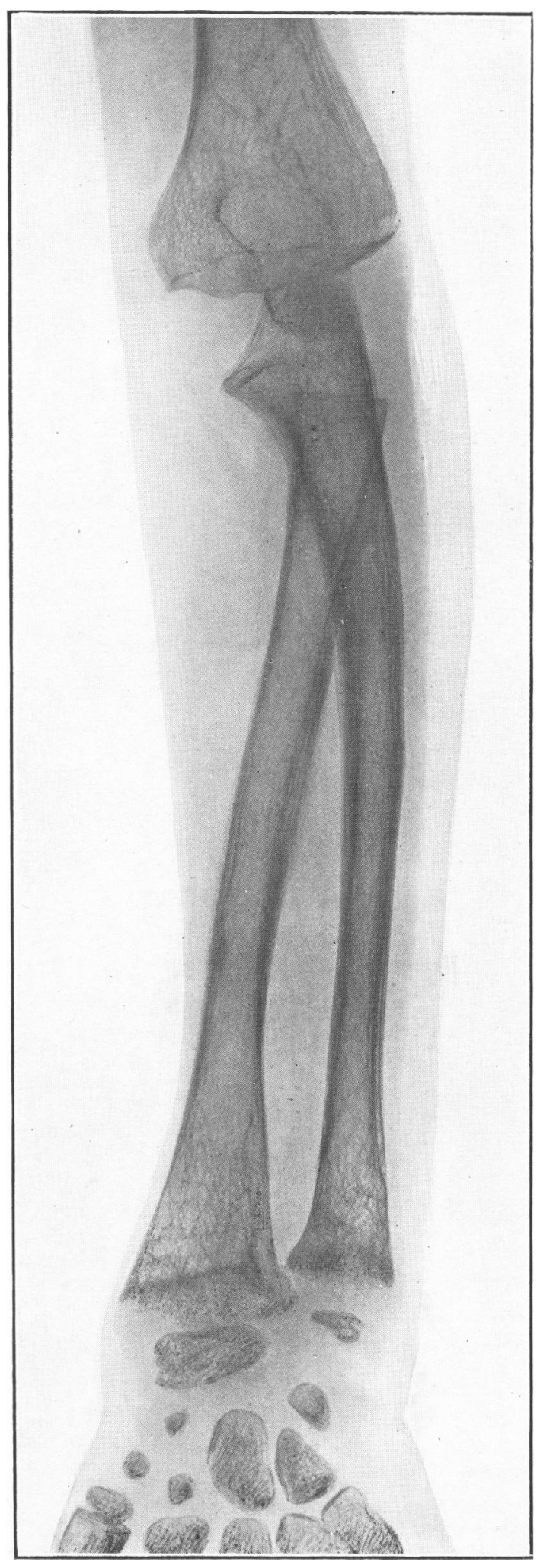

Fig. 6. 


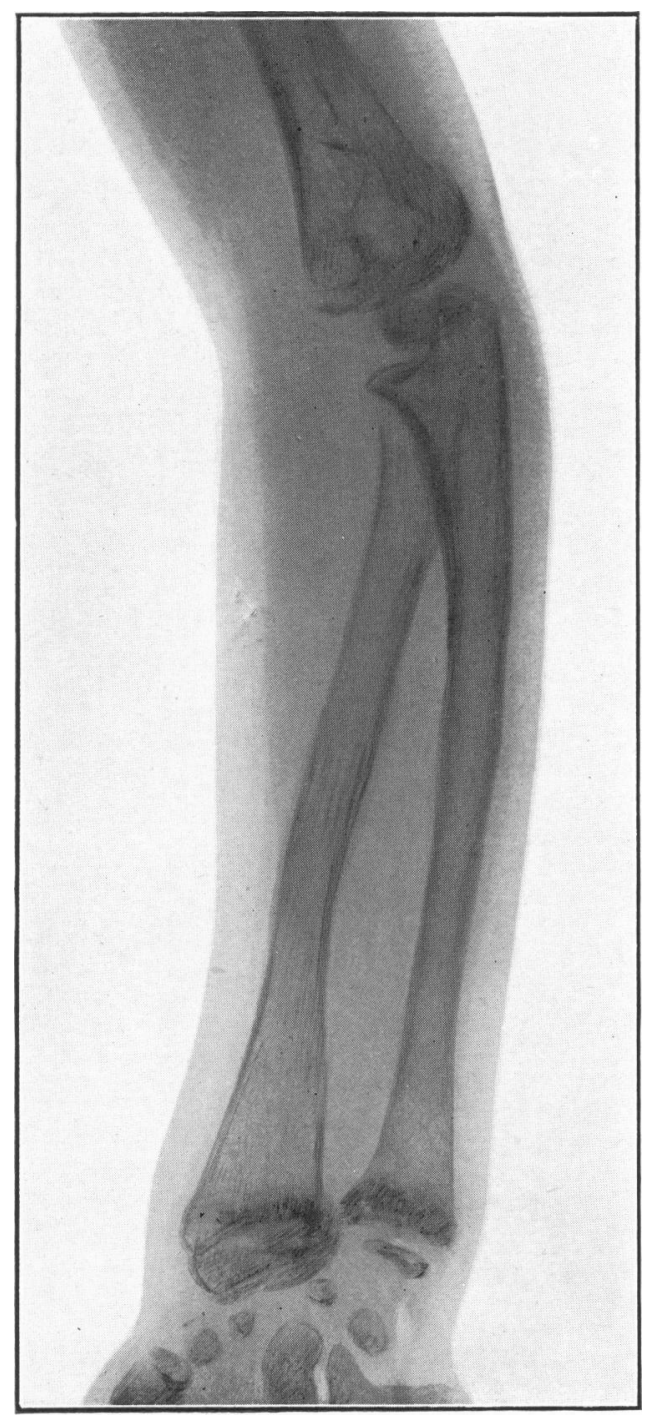

Fig. 7.

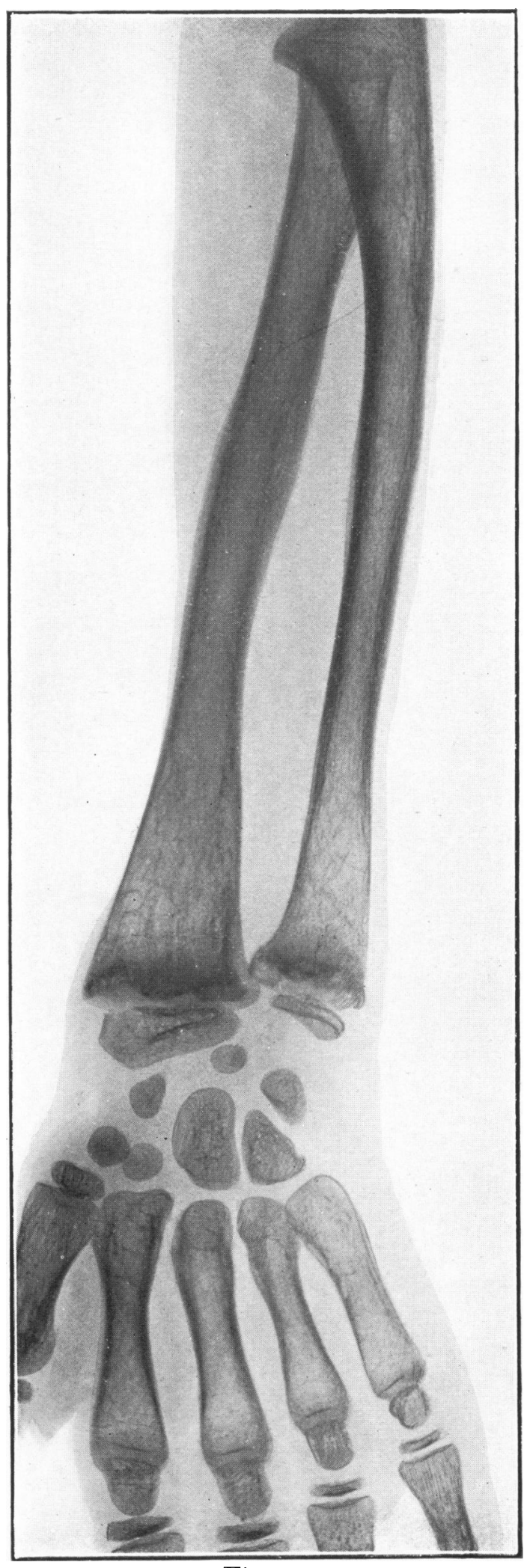

Fig. 8. 


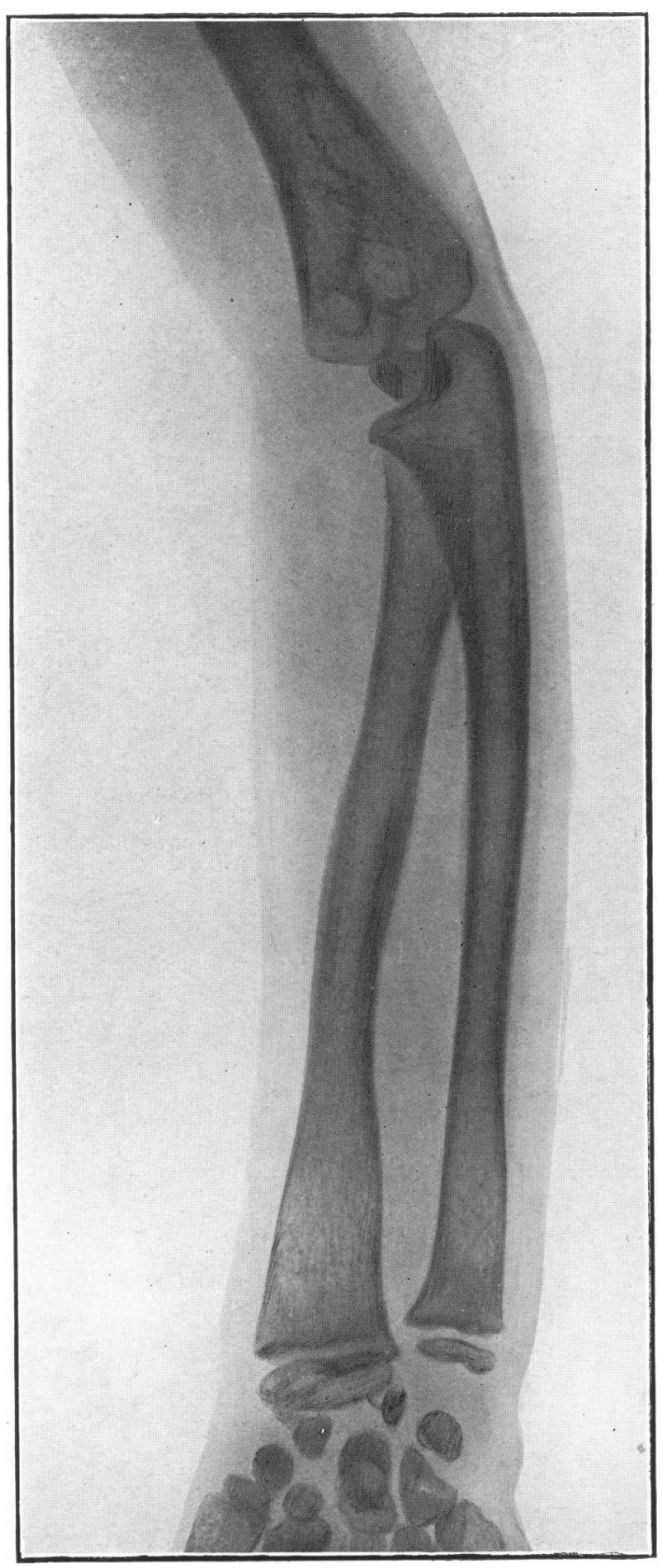

Fig. 9.

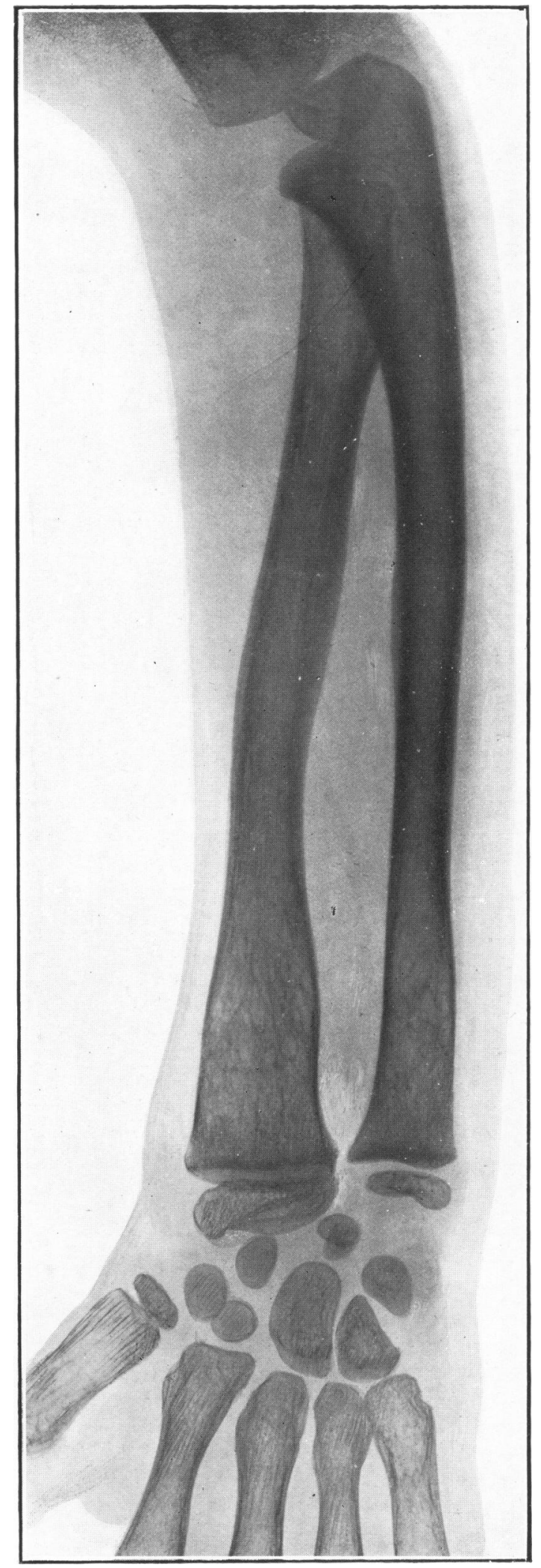

Fig. 10. 

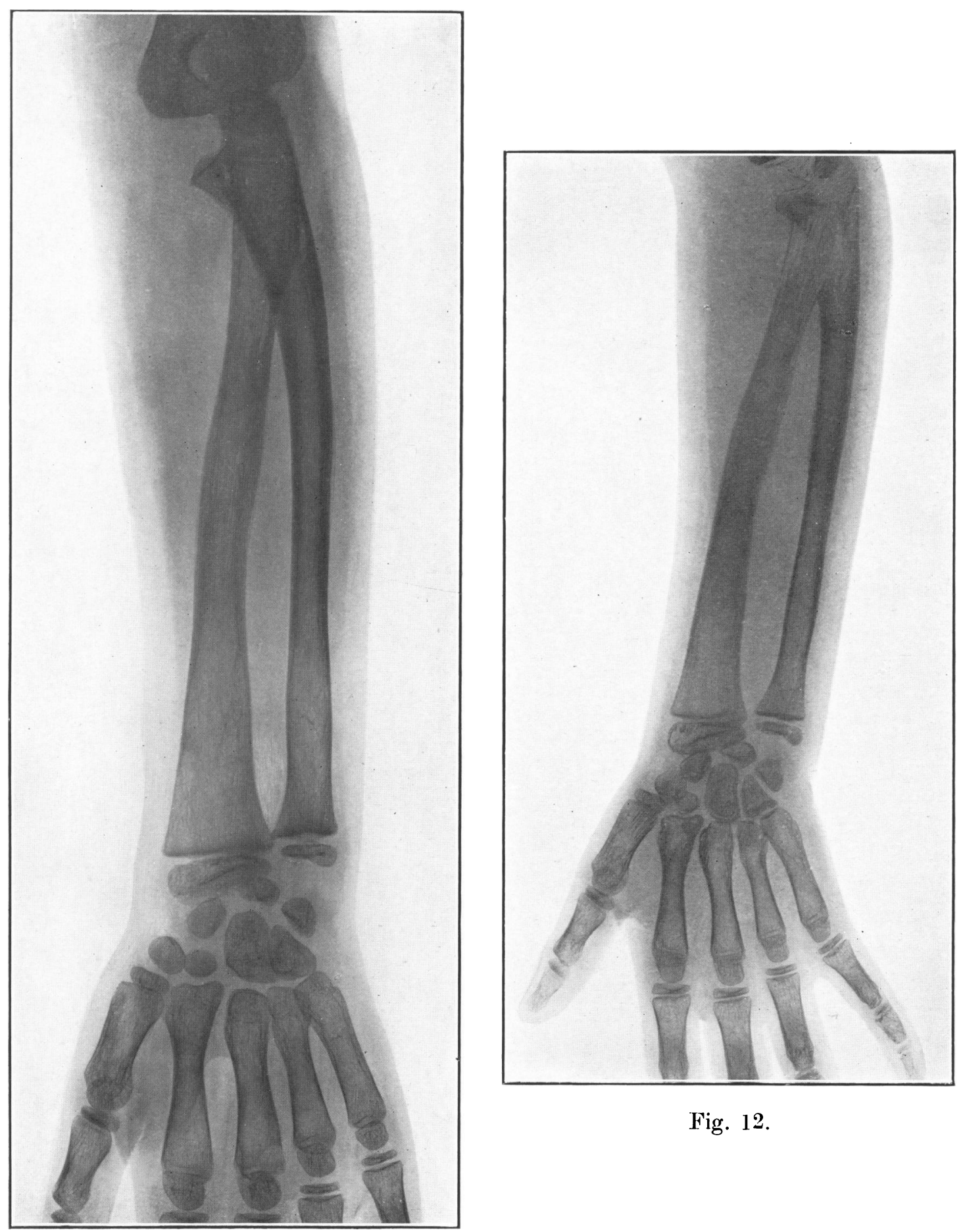

Fig. 12.

Fig. 11 . 

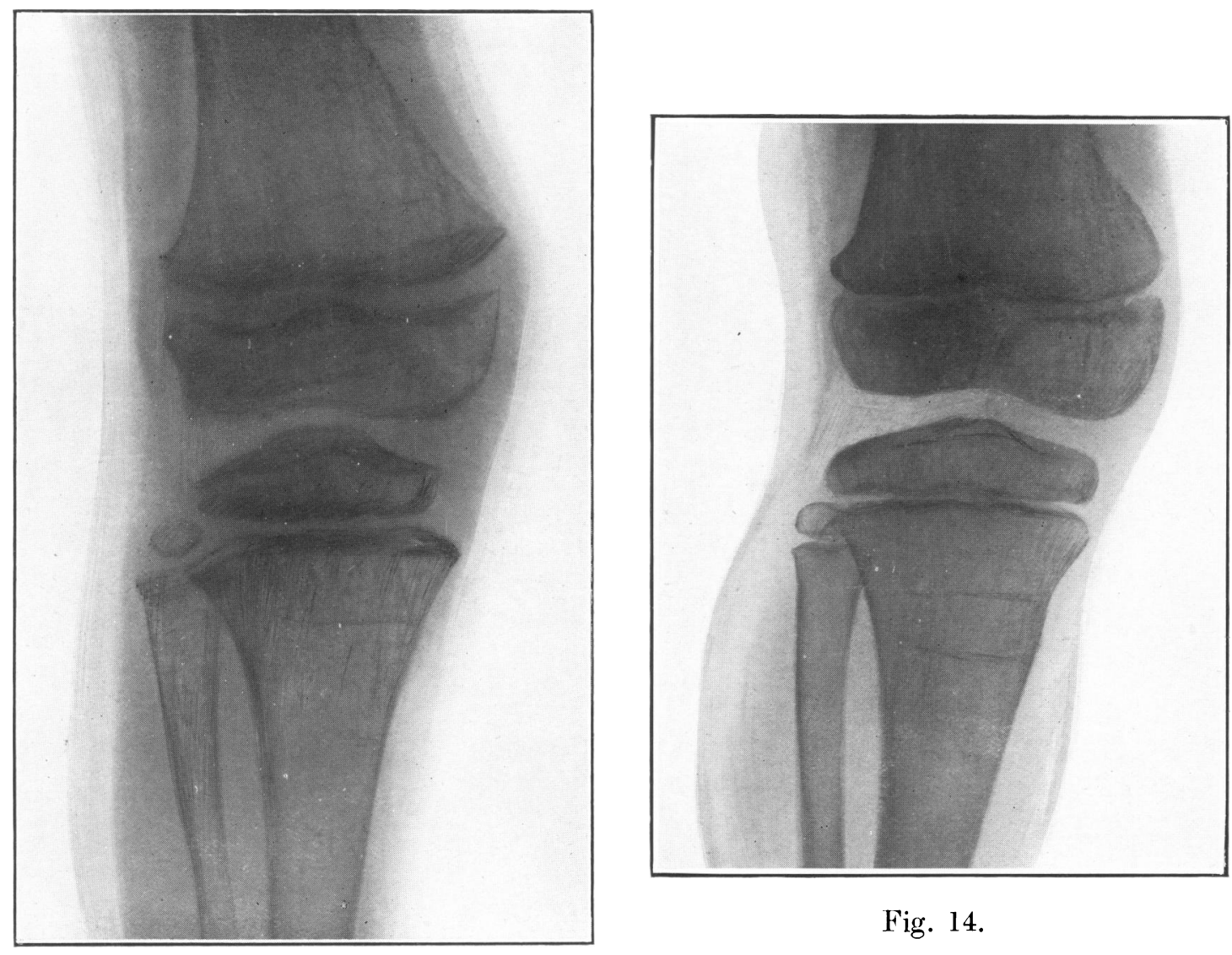

Fig. 14.

Fig. 13. 


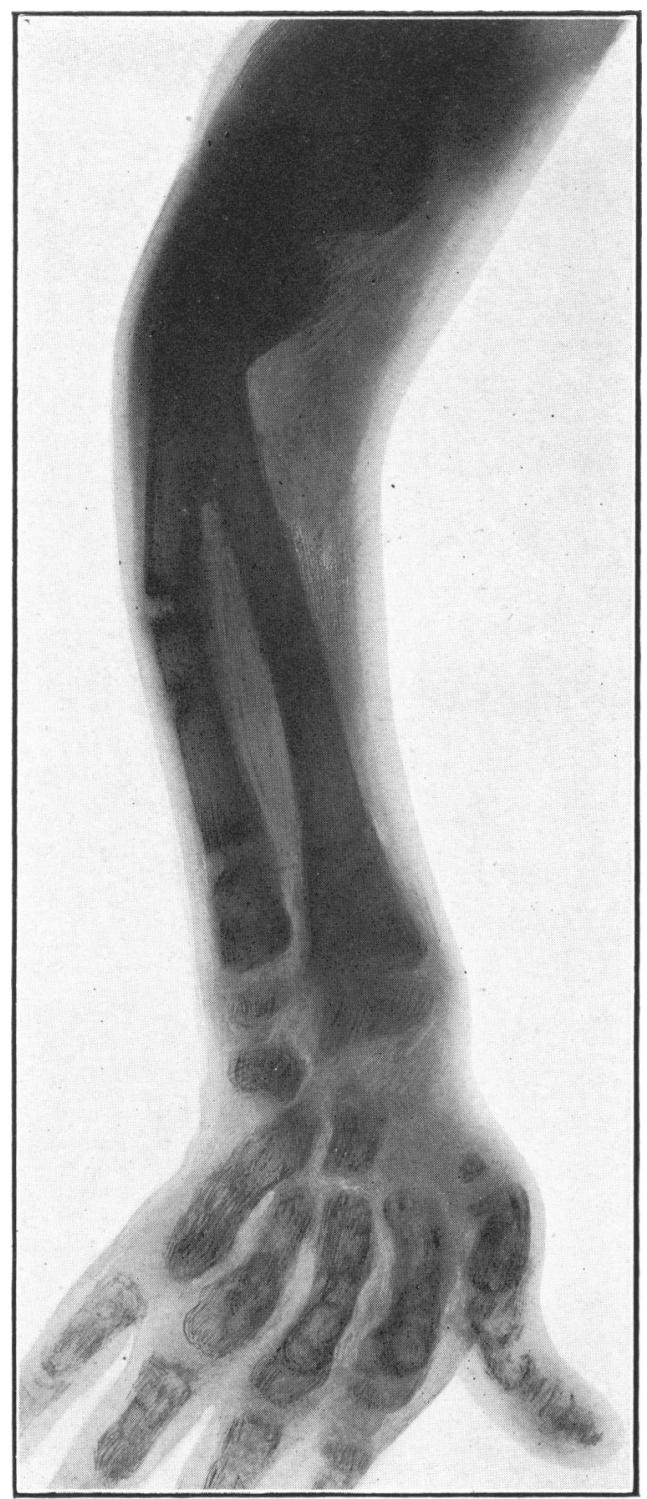

Fig. 15.

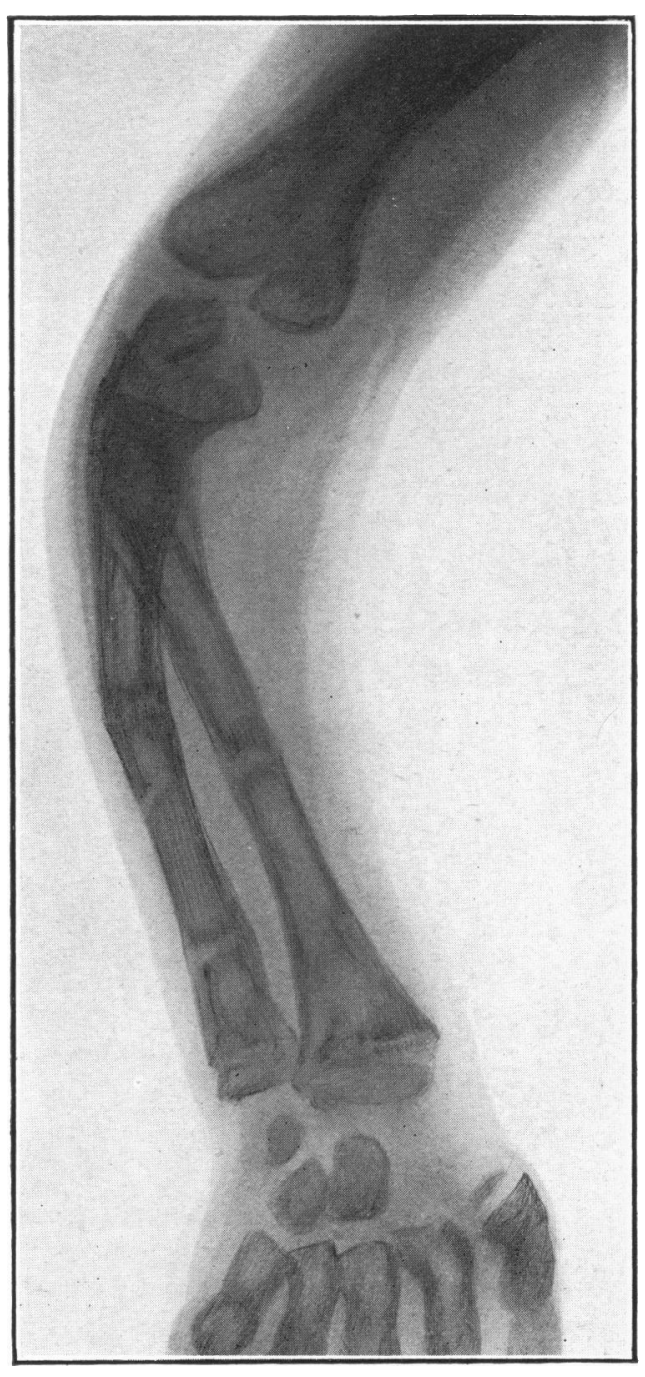

Fig. 16. 


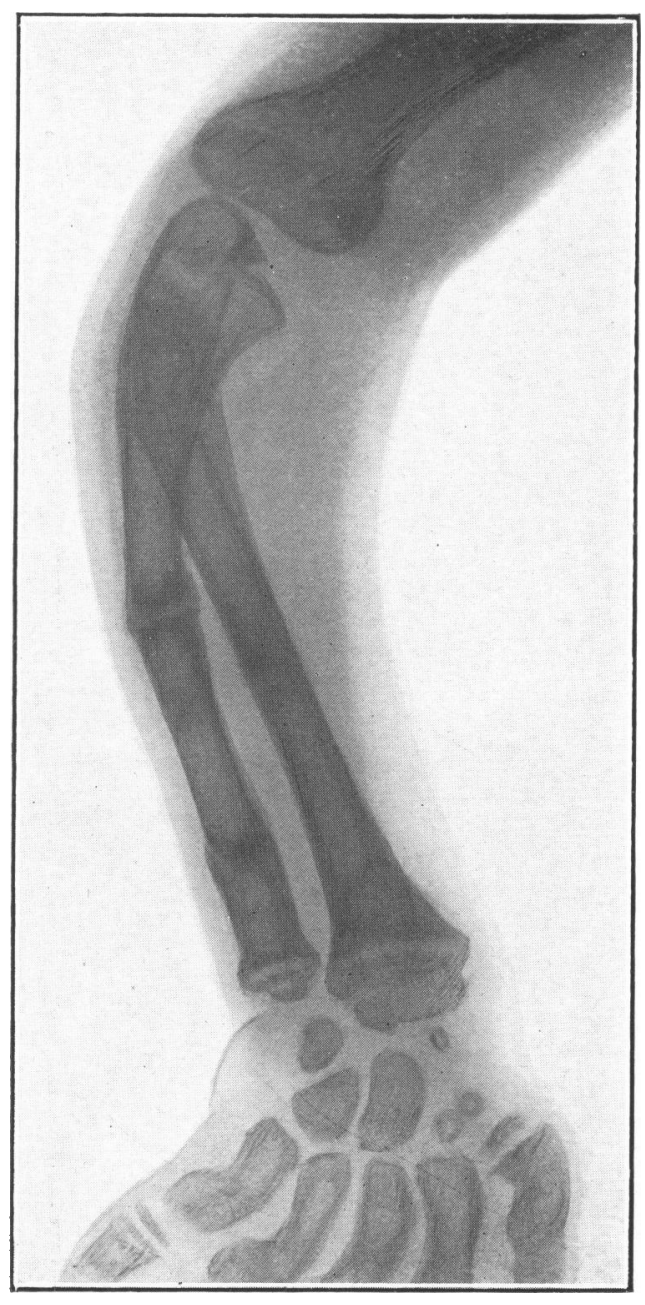

Fig. 17.

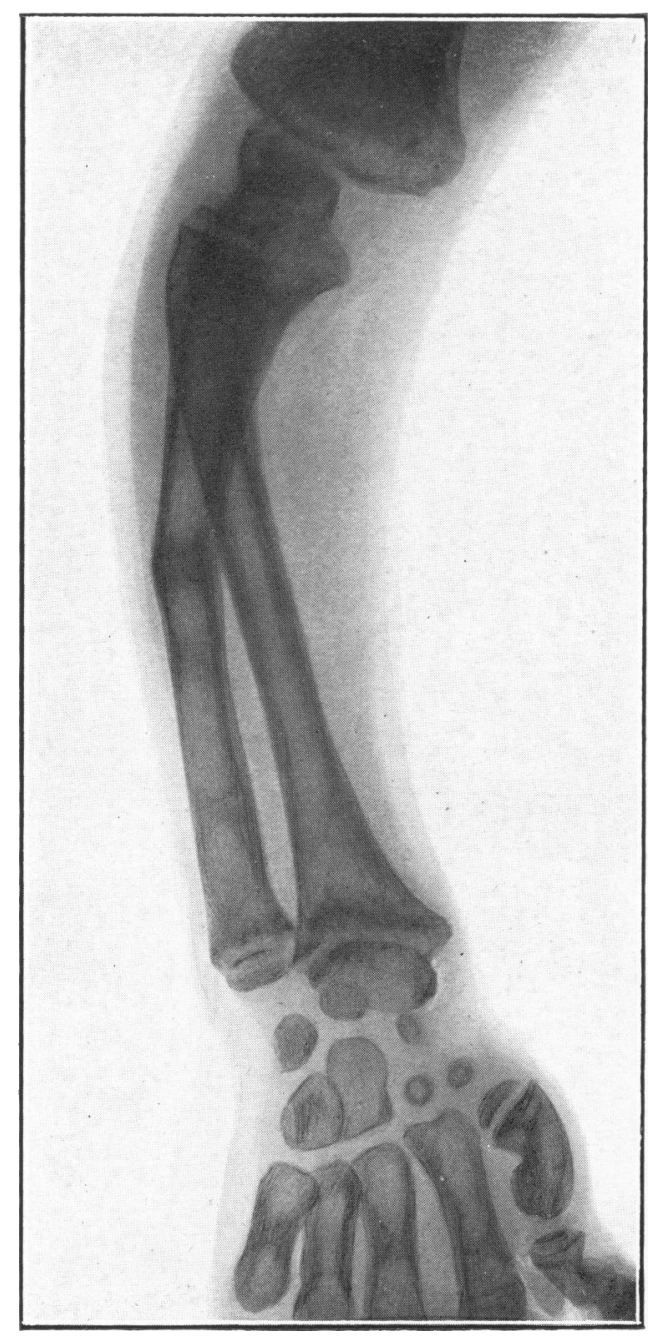

Fig. 18 . 


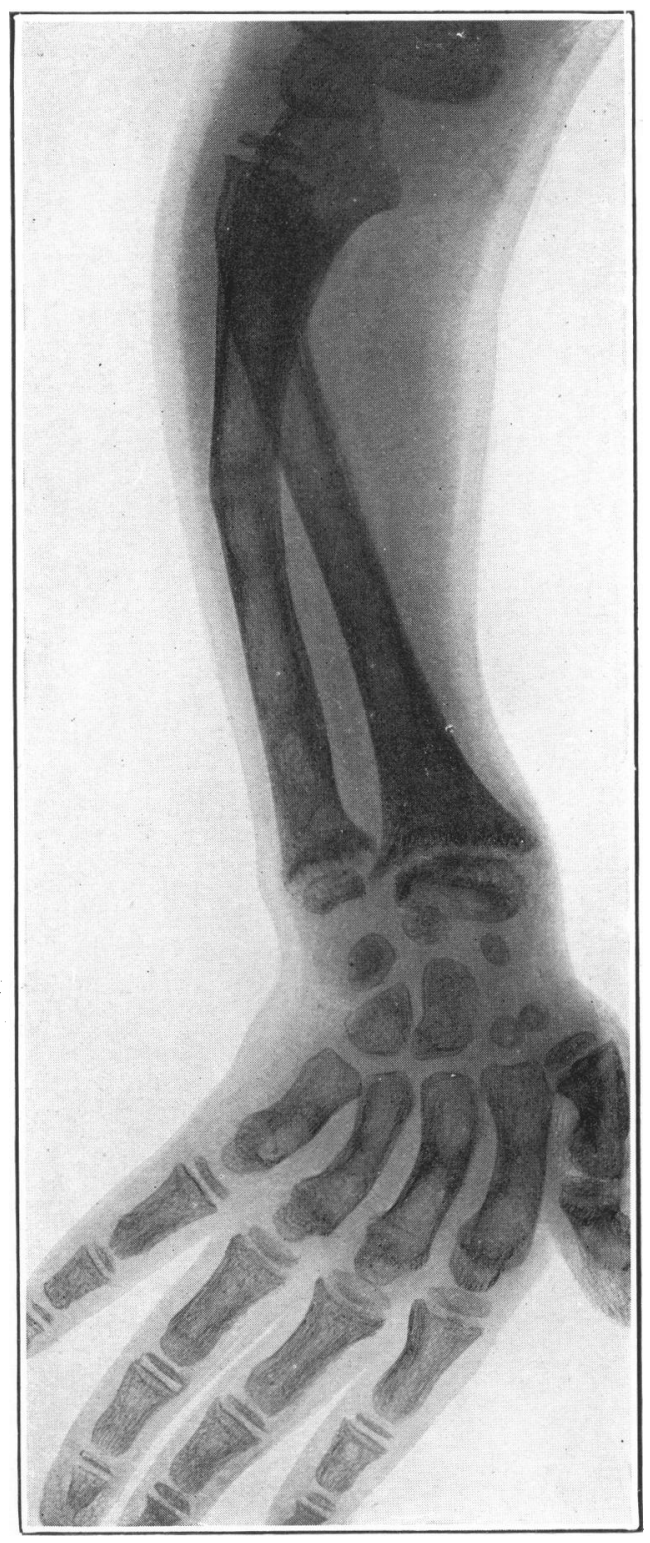

Fig. 19.

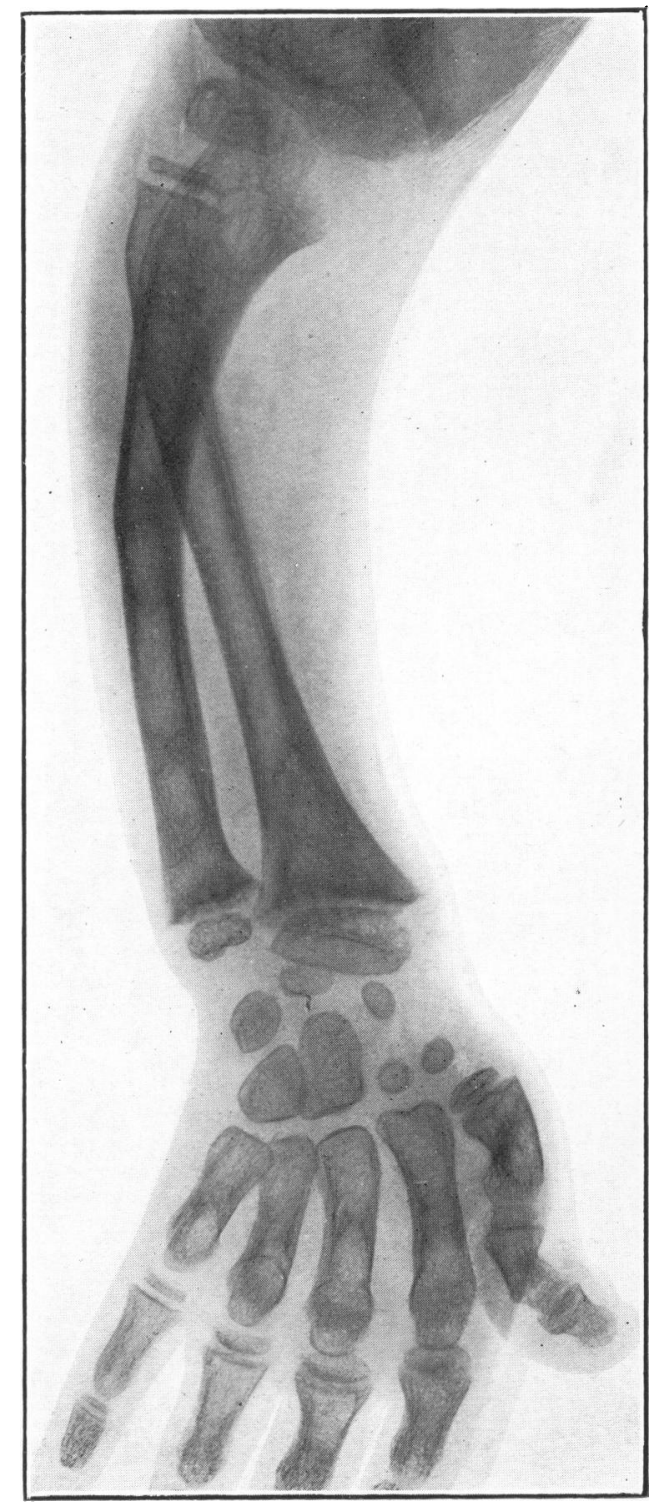

Fig. 20. 


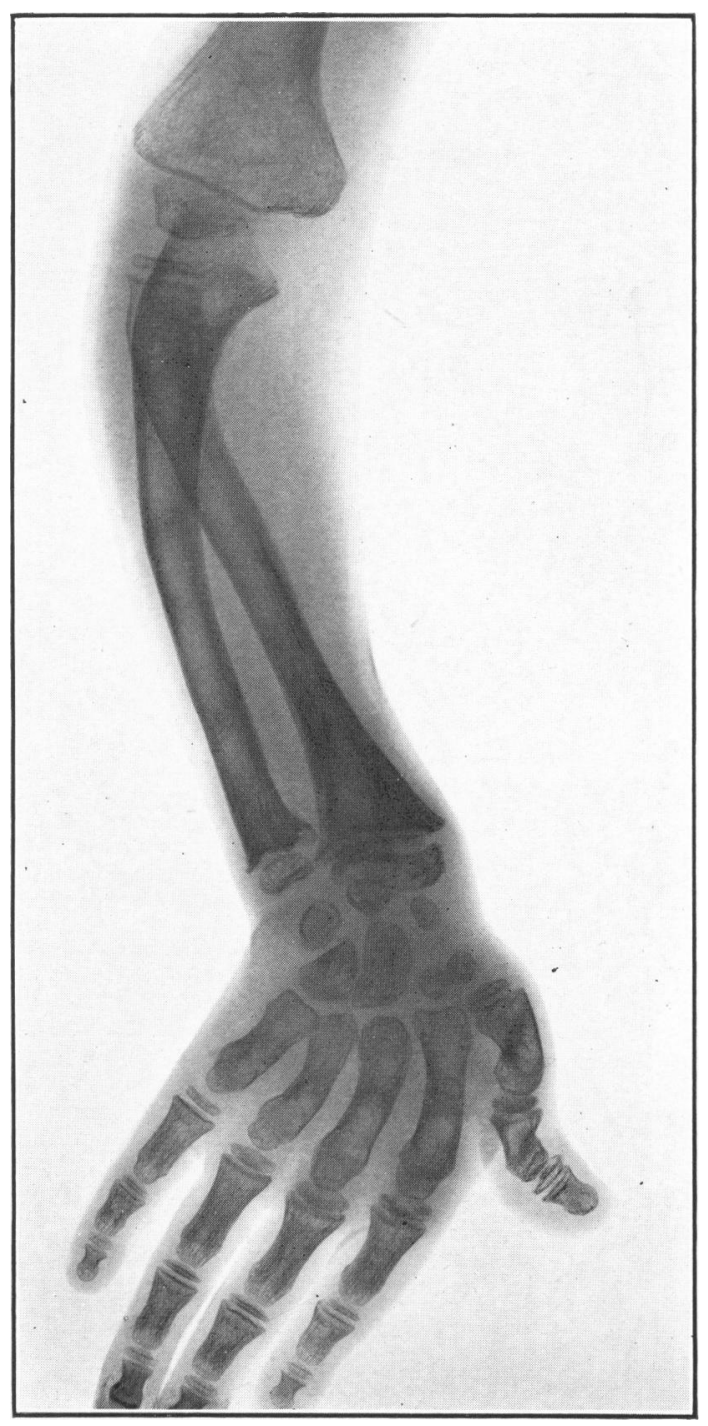

Fig. 21 .

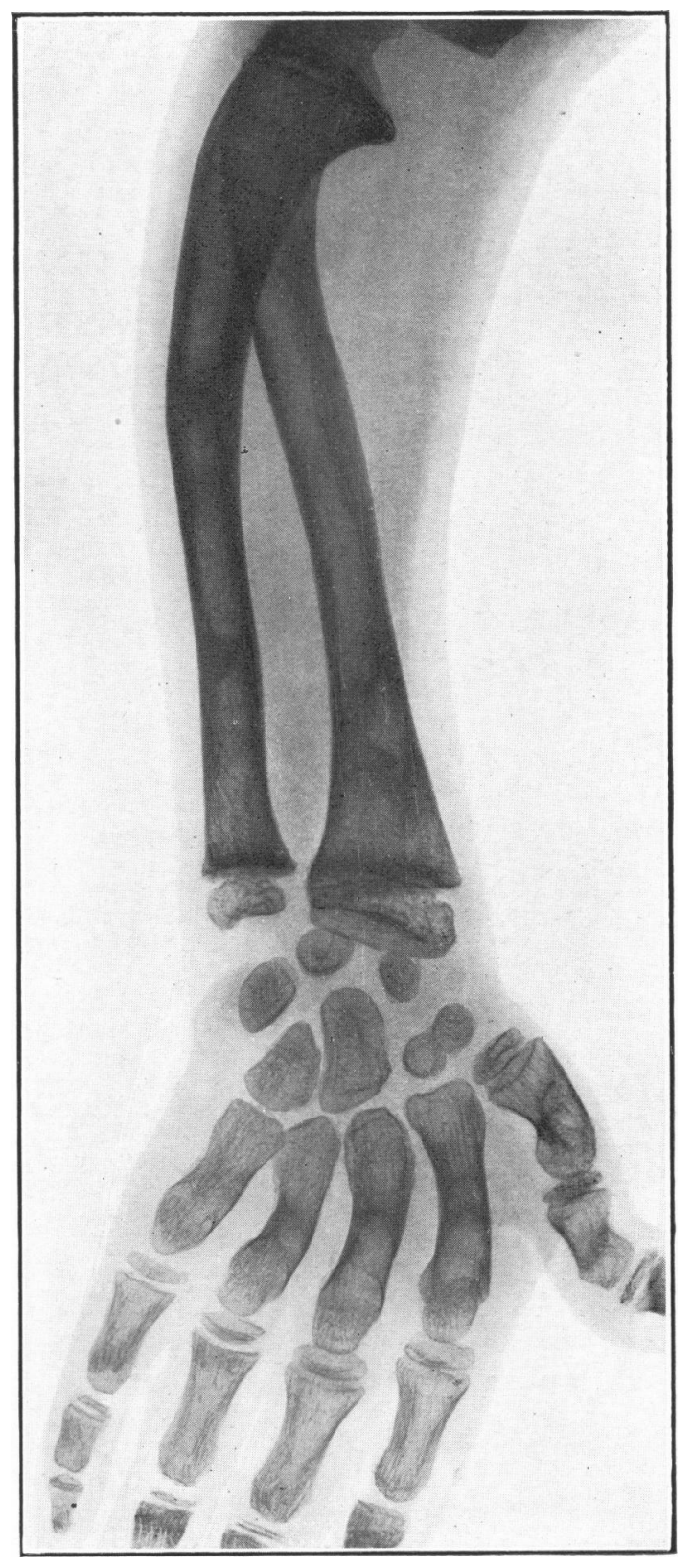

Fig. 22. 